\section{Coagulation/Fibrinolysis and Thrombosis in Coronavirus Disease 2019: A Review Based on
Up-To-Date Knowledge}

\section{Shoji Haruta*}

Department of Cardiology, Tokyo Women's Medical University, Yachiyo Medical Center, Chiba, Japan

\begin{abstract}
Introduction: Coronavirus disease (COVID-19) is an infectious disease caused by severe acute respiratory syndrome coronavirus 2 (SARS-CoV-2) that developed into an ongoing pandemic. The main pathology of COVID-19 is viral pneumonia, but thrombotic complications are frequently observed and are associated with its severity.
\end{abstract}

Methods: We selected qualitatively and quantitatively reliable reports, which were related to thrombosis and were associated with COVID-19, using the Google Scholar and PubMed search engines. The features of abnormal coagulation/fibrinolysis and thrombosis were reviewed based on these reports.

Results: Thrombosis accompanying COVID-19 can occur in veins, arteries, and capillaries. Macrothrombosis and microthrombosis can also occur. Furthermore, the patterns of disseminated intravascular coagulation that accompany COVID-19 can vary from the fibrinolysissuppressing to the fibrinolysis-enhancing type.

Discussion: Coagulation/fibrinolysis abnormalities in patients with COVID-19 should be investigated over time using many markers, including D-dimer levels. Based on the obtained results, prospective randomized clinical trials on antithrombotic drugs should be conducted to establish an effective treatment.

Conclusion: Further elucidation of the characteristic pathology of coagulation/fibrinolysis and thrombosis in patients with COVID-19

*Corresponding author: Shoji Haruta, Department of Cardiology, Tokyo Women's Medical University, Yachiyo Medical Center, 477-96, Oowada-shinden, Yachiyo, Chiba, Japan, Tel: +81 47450 6000; Fax: +81 47450 7047; E-mail: haruta.shoji@twmu.ac.jp

Citation: Haruta S (2020) Coagulation/Fibrinolysis and Thrombosis in Coronavirus Disease 2019: A Review Based on Up-To-Date Knowledge. J Emerg Med Trauma Surg Care S1: 006.

Received: October 12, 2020; Accepted: October 14, 2020; Published: October 21, 2020

Copyright: @ 2020 Haruta S. This is an open-access article distributed under the terms of the Creative Commons Attribution License, which permits unrestricted use, distribution, and reproduction in any medium, provided the original author and source are credited. is expected, which would lead to the development of appropriate treatments.

Keywords: Coagulation; COVID-19; Fibrinolysis; Thrombosis

\section{Introduction}

Approximately $80 \%$ of patients with coronavirus disease (COVID-19), caused by severe acute respiratory syndrome coronavirus 2 (SARS-CoV-2), have mild symptoms or remain asymptomatic; however, $20 \%$ of them exhibit severe symptoms or die in the worst-case scenario [1-3]. Even young people and those without complications can present severe symptoms. There are many unknown factors that could determine the outcome. Respiratory failure is the most common cause of death; however, excessive inflammatory reaction, coagulation activation with so-called cytokine storms, thrombosis, disseminated intravascular coagulation (DIC), and multiple organ failure can also result in death [4-8]. Herein, we review previous reports of coagulation and thrombus formation in patients with COVID-19 and describe the challenges and possible treatments.

\section{Various Thrombotic Events Associated with COVID-19}

COVID-19 can cause thrombi in arteries, veins, and capillaries. Pulmonary thromboembolism (PTE) is an extremely common and important complication of COVID-19 that can also be a direct cause of death. In a series of 12 autopsies reported by Wichmann et al., deep vein thrombosis (DVT) was observed in seven patients (58\%), with PTE being a direct cause of death in four of them (30\%) [9].

DVT and PTE can generally present simultaneously, and they are collectively referred to as venous thromboembolism (VTE). PTE is also found in patients with COVID-19 in the absence of DVT; thus, there is probably a mechanism through which thrombi are formed directly in the pulmonary artery, unlike the usual mechanism underlying PTE onset.

A study of 184 patients with severe COVID-19 who were admitted to the intensive care unit (ICU) showed that 75 of them exhibited thrombi [10]. A breakdown of patients presenting with thrombotic events was as follows: PTE, 65 patients; DVT, three patients; cerebral infarction, five patients; and arterial embolism, two patients. Severely ill patients predominantly presented with PTE, but not many patients presented with DVT. The prophylactic administration of anticoagulants did not suppress the onset of thrombosis.

Another study reported that VTE was observed in approximately $60 \%$ and $10 \%$ of patients admitted to the ICU and general ward, respectively (severely and mildly ill patients, respectively) [11]. The cumulative incidence of VTE gradually increased among patients admitted to the ICU and general ward up to 3 weeks and 1 week of hospitalization, respectively; however, no subsequent new-onset cases were observed in either group. Especially, it was considered that VTE measures at the early stage of hospitalization are important. VTE 
Citation: Haruta S (2020) Coagulation/Fibrinolysis and Thrombosis in Coronavirus Disease 2019: A Review Based on Up-To-Date Knowledge. J Emerg Med Trauma Surg Care S1: 006.

also occurred in this report, despite the preventative administration of anticoagulant therapy.

The presence of arterial and venous thrombosis is a characteristic of COVID-19. It has also been reported that cerebral infarction occurred in young people without any underlying diseases and even among patients who showed no symptoms of COVID-19 [12]. Cerebral infarction was observed in $3-5 \%$ of patients with venous thrombosis $[13,14]$. Acute coronary syndrome was present in $20 \%$ of patients with severe COVID-19 and was a complication associated with poor prognosis [15]. It was also reported that vasculitis-like findings similar to those of Kawasaki disease were observed in children, which were thought to be associated with vasculitis along with thrombosis [16]. Arterial thrombi might also be observed in the extremities, which were thought to cause ischemic necrosis in severe cases. The latter was also thought to be associated with the so-called "COVID toe" condition, which is characterized by painful redness of the toes [17].

Macrothrombosis, such as pulmonary embolism, can be diagnosed based on contrast-enhanced computed tomography findings; however, autopsy studies have clarified the presence of multiple microthrombi at the microscopic level, which cannot be diagnosed by imaging. Autopsy studies conducted by Fox et al. revealed the presence of macroscopic thrombi in the peripheral blood vessels in the lung and an enlarged right ventricle. Simultaneously, microscopic examination revealed thrombi in the pulmonary arterioles and venules [18]. These thrombi contained fibrin and platelets. The pathophysiology underlying thrombotic microangiopathy (TMA) in the lung probably contributed to the accompanying vascular endothelial injury, and this is a topic for a future study. Autopsy studies conducted by Lax et al. also showed that 10 out of 11 patients exhibited thrombi in the small and mid-sized pulmonary arteries despite undergoing prophylactic anticoagulant therapy, while eight patients exhibited infarctions [19]. Notably, VTE was not diagnosed in any patient while they were alive. In autopsy studies, Carsana et al. observed microthrombi (with platelets and fibrin) in small-sized pulmonary arteries in $33 / 38$ patients (87\%) [20]. The D-dimer levels increased to more than 10 times the upper normal limit in all 26 patients who were examined. Interestingly, alveolar hemorrhage, in addition to thrombi, was observed at the same frequency (33/38 patients; $87 \%$ ). There are also no data on the numbers of platelets, fibrinogen, thrombin-antithrombin complexes (TAT), and plasmin- $\alpha 2$ plasmin inhibitor complexes, but fibrinolysissuppressing DIC may have transformed into fibrinolysis-enhancing DIC at the time of death in at least some patients. Rapid decreases in the fibrinogen levels, which were previously high, and increases in fibrinogen-fibrin degradation product (FDP) and D-dimer levels were observed within 3 days among fatal cases. Although thrombotic events are emphasized in patients with COVID-19, care must be taken as rapid hemorrhages can also occur [21].

An interesting report compared COVID-19 with acute respiratory distress syndrome caused by the influenza virus [22]. Remarkably, diffuse alveolar damage was observed both in patients with COVID-19 and those with influenza. Wide-ranging thrombotic events accompanying severe vascular endothelial (presence of viruses in endothelial cells and destruction of cell membranes) and microvascular injuries were observed in patients with COVID-19. Microthrombi within pulmonary capillary vessels were nine times more frequent among patients with COVID-19 than among those with influenza. Angiogenesis was 2.7 times more frequent among patients with COVID-19 than among those with influenza; however, angiogenesis does not have normal functions, and it is considered that this process spurred thrombus formation. There is also the idea that this should not be referred to as a general DIC but as pulmonary intravascular coagulopathy with regards to such microthrombosis, which frequently occurs across a wide area of the lungs because thrombi tend to form systematically due to a strong inflammatory reaction expressed as a cytokine storm, while pulmonary thrombi are predominant [23-25].

The formation of thrombi in microcirculatory systems, such as arterioles, venules, and capillaries, could damage important organs. This type of multi-organ damage associated with thrombus formation in the microcirculatory system was initially thought to be a DIClike pathology often observed during bacterial infections. However, it has been recognized that the mechanisms underlying coagulation abnormalities in patients with COVID-19 and the examination results may differ from these initial beliefs [26]. Microcirculatory system disorders often result in altered consciousness and renal damage. As these symptoms are frequently encountered in TMA, it is presumed that there is a partially common underlying mechanism [27].

\section{Pathophysiology of Coagulation Abnormalities and Thrombus Formation in Patients with COVID-19}

It is difficult to identify a known viral infection that induces thrombotic tendencies that are comparable to those of COVID-19. Such significant thrombosis was not observed in SARS, which is caused by a similar coronavirus that was prevalent from 2002 to 2003, and Middle East respiratory syndrome, which was reported in 2012 [28,29]. High fever and DIC-like hemorrhagic coagulation abnormalities are frequently observed in viral diseases, such as Ebola hemorrhagic fever and dengue fever [30,31]. It is considered that hemorrhaging symptoms are generally not observed in patients with COVID-19, which is a similar RNA viral infection. The problems are thrombus formation and multiple organ failure caused by hypercoagulation. The origins of these differences remain unclear, but the causative virus of COVID-19, SARS-CoV-2, infects the vascular endothelium through angiotensin-converting enzyme 2 receptors. Factor VIII, which is a coagulation factor released by the infected vascular endothelium, and von Willebrand factor, which stimulates platelet adhesion, activate the coagulation system and platelet aggregation [32]. Factor VIII is activated by thrombin, forms tenase along with activated factor IX, and induces significant activation of coagulation in activated platelets (Figure 1).

The appearance of lupus anticoagulants, which accelerate blood coagulation and platelet aggregation, and the activation of complements that damage the vascular endothelium, are also observed in patients with COVID-19. The similarity of this disease with other thrombotic diseases (i.e., antiphospholipid antibody syndrome and TMA) that share this mechanism, has been indicated [33]. Cytokine storms due to excessive cytokine production are also thought to induce thrombotic tendencies. This is a condition observed in hemophagocytic syndrome, and some commonalities can be found in both diseases. However, the blood test findings and clinical characteristics do not entirely match those of any of the aforementioned diseases. Therefore, hypercoagulation states in patients with COVID-19 should be considered as a unique coagulation abnormality. 


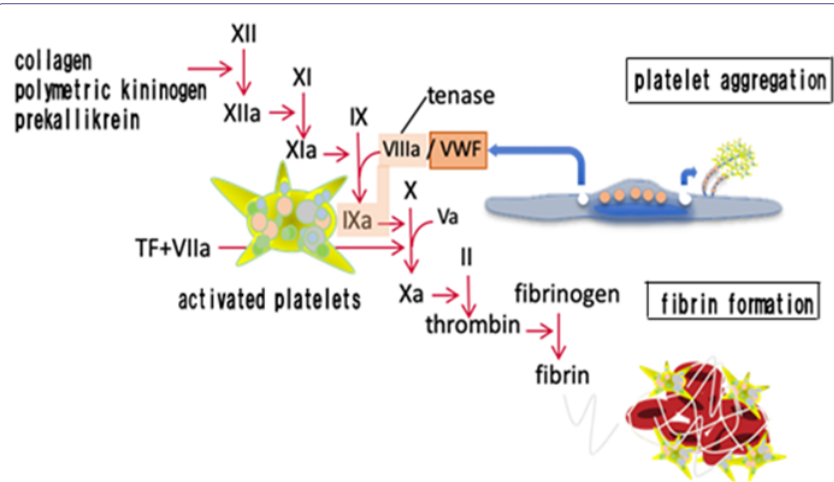

Figure 1: Vascular endothelial cell abnormalities and activation of coagulation/platelets.

Increases in blood D-dimer levels are most often reported in association with coagulation/fibrinolysis in patients with COVID-19. Many reports have indicated an association between the increased D-dimer levels and prognosis [34-36]. D-dimers are observed in the blood, as polymers of stabilized fibrin (fibrin cross-linked by factor XIII) degraded by plasmin. Especially, thrombi formation within the body due to coagulation activation, which is then degraded by fibrinolysis activation, may result in D-dimer formation. Many reports have indicated that increases in D-dimer levels are associated with severity, but may also be mild even if a large amount of thrombus is found in the body, in cases where they are not dissolved (a most serious scenario in the body). Specifically, fibrinolysis-suppressing DIC associated with sepsis may be characterized by relatively low increases in D-dimer levels even in severe and lethal cases [37]. To date, most reports on coagulation/fibrinolysis in patients with COVID-19 predicted prognosis based on their D-dimer levels at the time of hospital admission, and there are few reports that show changes over time. Of the coagulation/fibrinolysis tests, D-dimer and prothrombin time (PT) measurements were also generally performed, but there were few measurements of fibrinogen, activated partial thromboplastin time (APTT), and fibrinogen/FDP. Furthermore, no reports have investigated the TAT or plasmin- $\alpha 2$ plasmin inhibitor complex, which are essential markers for observing coagulation and fibrinolysis activation.

Tang et al. reported a valuable work focused on the dynamic fluctuations in coagulation and fibrinolysis among patients with COVID-19 (Figure 2) [4]. A retrospective analysis of the coagulation test results and outcomes of a series of 183 patients with confirmed novel coronavirus pneumonia showed an overall mortality rate of $11.5 \%$, with dead patients having significantly higher D-dimer and FDP levels at the time of hospital admission, and longer PT and APTT $(\mathrm{p}<0.05)$ compared to those in the survivors. The criteria for DIC were satisfied by $71.4 \%$ and $0.6 \%$ of dead patients and survivors, respectively, during hospitalization. Coagulation abnormalities, particularly abnormal D-dimer and FDP levels, significantly increased among dead patients due to COVID-19. The most notable point was the severe coagulation abnormalities observed on days 10 and 14 among non-survivors. The D-dimer, FDP, and fibrinogen levels were approximately $20 \mu \mathrm{g} / \mathrm{mL},>100 \mu \mathrm{g} / \mathrm{mL}$, and approximately 100 $\mathrm{mg} / \mathrm{dL}$, respectively. PT levels increased but the increases in APTT levels or decreases in antithrombin levels were not pronounced. These findings differed considerably from those of fibrinolysissuppressing DIC caused by sepsis and if anything, matched those of fibrinolysis-enhancing DIC [37]. Interestingly, there were large fluctuations in biomarker levels on days 7 and 10. Especially, the fibrinogen levels tended to be high on day 7 but decreased drastically within 3 days. The FDP and D-dimer levels also increased rapidly within 3 days. Meanwhile, the survivors showed almost no fluctuations during this period. Fibrinolysis-suppressing DIC may have transformed to fibrinolysis-enhancing DIC in very severe cases. These types of changes in pathophysiology may be missed when the coagulation/fibrinolysis markers are not tracked over time. One report recommended the performance of total fibrinolytic therapy for patients with COVID-19 [38]; however, there is a concern that massive hemorrhaging may occur when fibrinolytic therapy is administered to patients with fibrinolysis-enhancing DIC. The high incidence of thrombi (particularly venous thromboembolism (VTE) has been noted in patients with COVID-19 and is often associated with disease severity [39]. However, considerable hemorrhaging in addition to thrombi has been observed in very severe cases, leading to death (autopsy cases) [18]. Changes in pathology must also reflect changes in treatment methods.

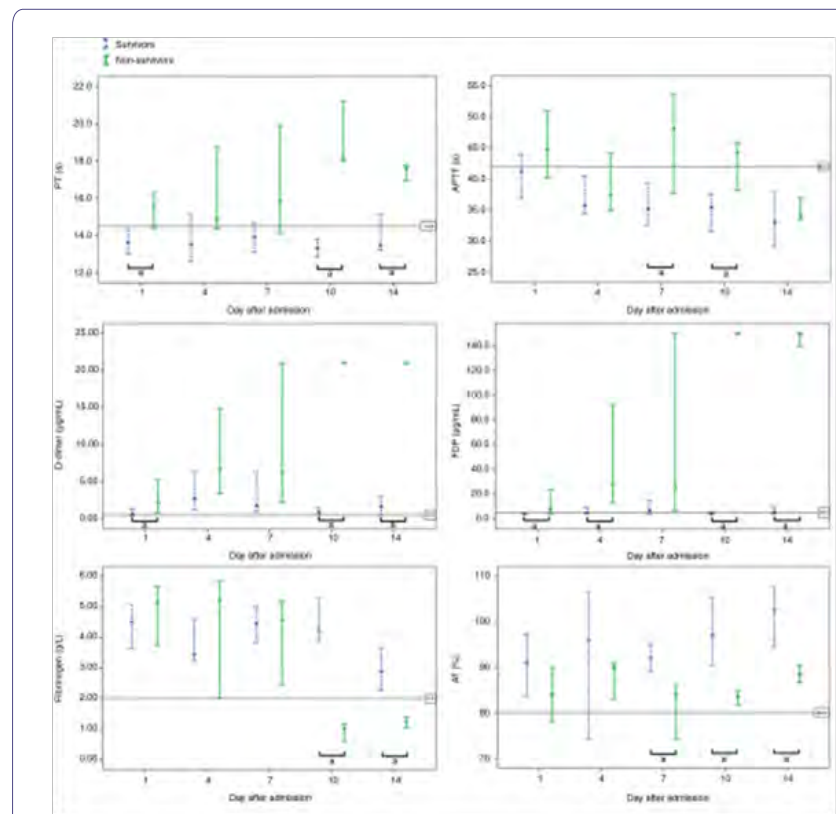

Figure 2: Dynamic profile of coagulation parameters in patients with NCP.

Timeline charts illustrate changes in coagulation parameters in 183 patients with COVID-19 (21 non-survivors and 162 survivors) after admission. The error bars show the medians and $25 \%$ and $75 \%$ percentiles. The horizontal lines show the upper normal limits of PT, APTT, D-dimer and FDP, and lower normal limits of fibrinogen and antithrombin activity [4]

${ }^{a} p<0.05$ for survivors vs. non-survivors

APTT: Activated Partial Thromboplastin Time; COVID-19: Coronavirus Disease; FDP: Fibrin Degradation Product; NCP: Novel Coronavirus Pneumonia; PT:Prothrombin Time

\section{Treatment of Thrombi Related to COVID-19}

Heparin is the most frequently used antithrombotic agent for COVID-19. Heparin exerts anticoagulant actions in an antithrombindependent manner, and it is expected to have antiviral and antiinflammatory effects among patients with COVID-19 [40-43]. Heparan sulfate exerts its antiviral effects by binding to the $\mathrm{S}$ proteins of SARS-CoV-2 and preventing the invasion of host cells, and its anti-inflammatory effects by binding to chemokines and damaging 
Citation: Haruta S (2020) Coagulation/Fibrinolysis and Thrombosis in Coronavirus Disease 2019: A Review Based on Up-To-Date Knowledge. J Emerg Med Trauma Surg Care S1: 006 .

associated molecular patterns. Reports have indicated that heparin administration affects the prognosis of COVID-19 patients. Heparin (unfractionated heparin or low-molecular-weight heparin) was shown to improve prognosis only in cases where the sepsis-induced coagulopathy score was $\geq 4$ and the D-dimer levels were $>6$ times higher than normal levels $(<0.5 \mu \mathrm{g} / \mathrm{mL})$ [44]. It is thought that the benefits of heparin are more likely to be exhibited in severe cases.

In a study that retrospectively compared patients who received anticoagulant therapy during hospitalization for COVID-19 to those who did not, effects on prognosis ( $\mathrm{n}=2,773$ in total) was examined that yielded patient mortality rates of $22.5 \%$ and $22.8 \%$ (14 days), respectively (median survival time: 21 days and 14 days, respectively). Among the patients who were placed on a ventilator $(\mathrm{n}=395)$, the mortality rates when anticoagulant therapy was and was not administered were $29.1 \%$ and $62.7 \%$, respectively (median survival time: 21 days and 9 days, respectively). Thus, the results exhibited the effectiveness of anticoagulant therapy, particularly in severe cases that required a ventilator [45].

Meanwhile, the incidences of VTE in severely ill patients with COVID-19 (placed on a ventilator) were $100 \%$ and $56 \%$ when "preventative" (unfractionated or low-molecular-weight heparin) and "therapeutic" anticoagulant therapies were administered, respectively. Thus, no satisfactory results were obtained [46]. A systematic review also showed that the incidence of VTE in patients admitted to the ICU (under preventative or therapeutic heparin administration) was 31\% [47]. There are many issues that need to be resolved, including the kind of heparin that should be used, the ideal dose, and whether it is necessary to combine it with other forms of antithrombotic therapy.

The complications of DIC are fairly frequent in patients with COVID-19; however, antithrombin concentrates (e.g., antithrombin gamma [genetic recombination]) should be concomitantly used for patients with DIC with decreased antithrombin.

There are no randomized controlled trials on direct-acting oral anticoagulants (DOACs) at the time of writing this manuscript. However, a retrospective study investigated the prognosis after the onset of COVID-19 based on whether seniors aged $>70$ years (median age, 79 years; 70-92 years, $\mathrm{n}=70$ ) were already taking DOACs for heart disease. The results showed that 26 patients (37.1\%) were taking DOACs, with seven, six, and 13 patients taking them for pulmonary embolism, DVT, and fibrillation, respectively. A breakdown of patients taking DOACs was as follows: rivaroxaban, 11 patients; apixaban, nine patients; edoxaban, four patients; and dabigatran, two patients. The analysis results showed that significantly better prognosis was observed in patients receiving DOACs $(\mathrm{p}=0.01$, log-rank test) [46]. DOACs are thought to be difficult to administer to severely ill patients because the drug is administered orally, but future developments are expected to control thrombotic tendencies in mild cases or after hospital discharge. However, caution is required because blood DOAC concentrations rapidly increase when antiviral therapy is administered against COVID-19 [47].

Reports have indicated the effectiveness of tissue plasminogen activators, which are therapeutic agents for fibrinolytic therapy and have stated that clinical trials should be conducted [48].
The International Society on Thrombosis and Hemostasis published provisional guidance for coagulation and fibrinolysis in patients with COVID-19 [49]. Monitoring of D-dimer levels, PT, platelet count, and fibrinogen levels is recommended (Figure 3). D-dimer values that are 3-4 times higher than the normal upper limit, increased PT, platelet counts $<100,000 / \mathrm{mm}^{3}$, and fibrinogen levels $<200 \mathrm{mg} / \mathrm{dL}$ are indications for hospitalization; these markers should be measured repeatedly every day following hospitalization. Lowmolecular-weight heparin administration at doses for preventing thrombosis or embolism should be commenced as long as there are no contraindications for the prevention of thrombotic/embolic complications. The diagnostic criteria for DIC should be used, and its onset should be monitored when test findings worsen. The selection of low-molecular-weight heparin was suggested by Tang et al., and this drug can be used worldwide. As there are no reports that serve as a basis for the ideal administered dosage, doses that prevent thrombosis or embolism are recommended.

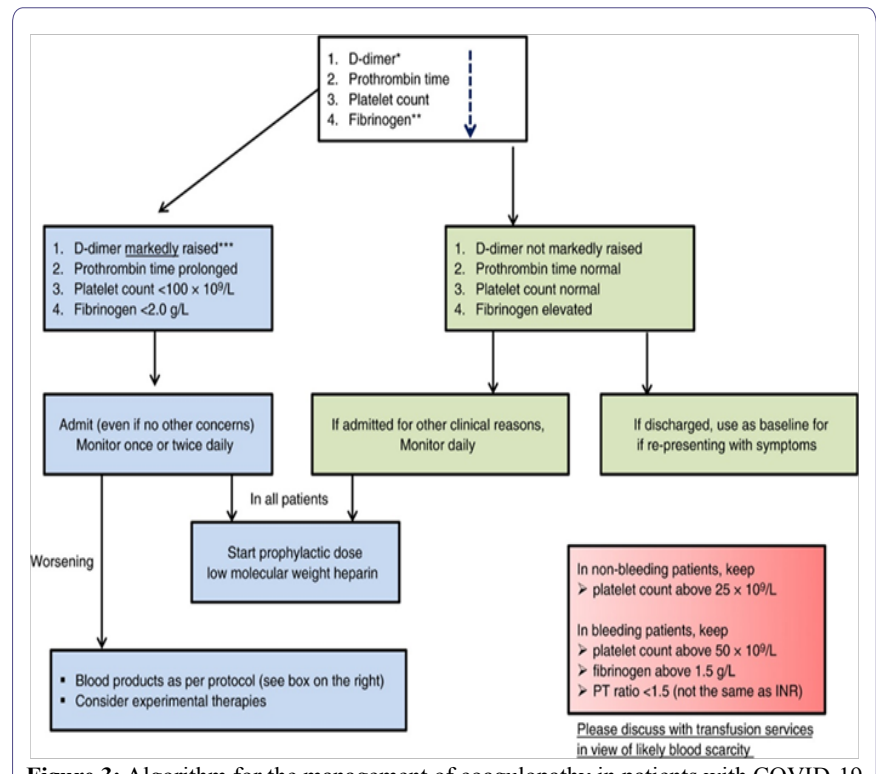

Figure 3: Algorithm for the management of coagulopathy in patients with COVID-19 based on simple laboratory markers.

*The list of markers is given in the decreasing order of importance

**Performing fibrinogen assays may not be feasible in many laboratories but monitoring the levels can be helpful after patient admission.

***Although a specific cut-off cannot be defined, a three-to-four-fold increase in D-dimer levels could be significant. Any one of the values in this flowchart may be considered significant [49].

COVID-19: coronavirus disease; PT: prothrombin time

\section{Conclusion}

Findings related to COVID-19 accumulate every day and must be updated to provide the latest information to the scientific community. However, many of these are retrospective observational studies, and their content must be examined carefully. Thrombi in patients with COVID-19 can also occur even if the patient is asymptomatic, and thrombotic complications can worsen prognosis in advanced cases. The early stage elucidation of coagulation/fibrinolysis in such patients, and the establishment of optimal antithrombotic drug administration based on the antithrombotic therapy indication/start time are required; therefore, randomized controlled trials should be conducted. 
Citation: Haruta S (2020) Coagulation/Fibrinolysis and Thrombosis in Coronavirus Disease 2019: A Review Based on Up-To-Date Knowledge. J Emerg Med Trauma Surg Care S1: 006.

\section{References}

1. Huang C, Wang Y, Li X, Ren L, Zhao J, et al. (2020) Clinical features of patients infected with 2019 novel coronavirus in Wuhan, China. Lancet 395: 497-506

2. Zhou F, Yu T, Du R, Fan G, Liu Y, et al. (2020) Clinical course and risk factors for mortality of adult inpatients with COVID-19 in Wuhan, China: a retrospective cohort study. Lancet 395: 1054-1062.

3. Guan WJ, Ni ZY, Hu Y, Liang WH, Ou CQ, et al. (2020) Clinical characteristics of coronavirus disease 2019 in China. N Engl J Med 382: 1708 1720 .

4. Tang N, Li D, Wang X, Sun Z (2020) Abnormal coagulation parameters are associated with poor prognosis in patients with novel coronavirus pneumonia. J Thromb Haemost 18: 844-847.

5. Mehta P, McAuley DF, Brown M, Sanchez E, Tattersall RS, et al. (2020) COVID-19: consider cytokine storm syndromes and immunosuppression. Lancet 395: 1033-1034.

6. Jose RJ, Manuel A (2020) COVID-19 cytokine storm: the interplay between inflammation and coagulation. Lancet Respir Med 8: e46-e47.

7. Wright DJM (2020) Prevention of the cytokine storm in COVID-19. Lancet Infect Dis S1473-3099: 30376-30385.

8. Iba T, Levy JH, Connors JM, Warkentin TE, Thachil J, et al. (2020) The unique characteristics of COVID-19 coagulopathy. Crit Care 24: 360 .

9. Wichmann D, Sperhake JP, Lütgehetmann M, Steurer S, Edler C, et al. (2020) Autopsy findings and venous thromboembolism in patients with COVID-19: a prospective cohort study. Ann Intern Med 173: 268-277.

10. Klok FA, Kruip MJHA, van der Meer NJM, Arbous MS, Gommers D, et al. (2020) Confirmation of the high cumulative incidence of thrombotic complications in critically ill ICU patients with COVID-19: An updated analysis. Thromb Res 191: 148-150.

11. Middeldorp S, Coppens M, van Haaps TF, Foppen M, Vlaar AP, et al. (2020) Incidence of venous thromboembolism in hospitalized patients with COVID-19. J Thromb Haemost 18: 1995-2002.

12. Oxley TJ, Mocco J, Majidi S, Kellner CP, Shoirah H, et al. (2020) Large-vessel stroke as a presenting feature of COVID-19 in the young. N Engl J Med 382: e60.

13. Klok FA, Kruip MJHA, van der Meer NJM, Arbous MS, Gommers DAMPJ, et al. (2020) Incidence of thrombotic complications in critically ill ICU patients with COVID-19. Thromb Res 191: 145-147.

14. Mao L, Jin H, Wang M, Hu Y, Chen S, et al. (2020) Neurologic manifestations of hospitalized patients with coronavirus disease 2019 in Wuhan, China. JAMA Neurology 77: 683-690.

15. Shi S, Qin M, Shen B, Cai Y, Liu T, et al. (2020) Association of cardiac injury with mortality in hospitalized patients with COVID-19 in Wuhan, China. JAMA Cardiol 5:802-810.

16. Viner RM, Whittaker E (2020) Kawasaki-like disease: emerging complication during the COVID-19 pandemic. Lancet 395: 1741-1743.

17. Noakes A, Majoe S (2020) Understanding the role that 'COVID toe' has in recognizing the potential extent of COVID-19 infections: a case study. Pathog Glob Health 114: 283-284

18. Fox SE, Akmatbekov A, Harbert JL, Li G, Quincy Brown J, et al. (2020) Pulmonary and cardiac pathology in African American patients with COVID-19: an autopsy series from New Orleans. Lancet Respir Med 8: 681-686.

19. Lax SF, Skok K, Zechner P, Kessler HH, Kaufmann N, et al. (2020) Pulmonary arterial thrombosis in covid-19 with fatal outcome: results from a prospective, single-center, clinicopathologic case series. Ann Intern Med $173: 350-361$.
20. Carsana L, Sonzogni A, Nasr A, Rossi RS, Pellegrinelli A, et al. (2020) Pulmonary post-mortem findings in a series of COVID-19 cases from northern Italy: a two-centre descriptive study. Lancet Infect Dis 20: 11351140 .

21. Fraissé M, Logre E, Pajot O, Mentec H, Plantefève G, et al. (2020) Thrombotic and hemorrhagic events in critically ill COVID-19 patients: a French monocenter retrospective study. Crit Care 24: 275.

22. Ackermann M, Verleden SE, Kuehnel M, Haverich A, Welte T, et al. (2020) Pulmonary vascular endothelialitis, thrombosis, and angiogenesis in COVID-19. N Engl J Med 383: 120-128.

23. McGonagle D, Sharif K, O'Regan A, Bridgewood C (2020) The role of cytokines including interleukin-6 in COVID-19 induced pneumonia and macrophage activation syndrome-like disease. Autoimmun Rev 19: 102537.

24. Fogarty H, Townsend L, Ni Cheallaigh C, Bergin C, Martin-Loeches I, et al. (2020) COVID19 coagulopathy in Caucasian patients. Br J Haematol 189: $1044-1049$

25. Belen-Apak FB, Sarıalioğlu F (2020) Pulmonary intravascular coagulation in COVID-19: possible pathogenesis and recommendations on anticoagulant/thrombolytic therapy.J Thromb Thrombolysis 50: 278-280.

26. Levi M, Thachil J, Iba T, Levy JH (2020) Coagulation abnormalities and thrombosis in patients with COVID-19. Lancet Haematol 7: e438-e440.

27. Marcilla Vázquez C, Vidal Company A, Navarro Felipe A, Alfaro Ponce B (2020) Thrombotic microangiopathy: A renal manifestation in SARSCoV-2 infection (COVID-19 disease). An Pediatr (Barc) S1695-4033. 30264-30672.

28. Booth CM, Matukas LM, Tomlinson GA, Rachlis AR, Rose DB, et al (2003) Clinical features and short-term outcomes of 144 patients with SARS in the greater Toronto area. JAMA 289: 2801-2809.

29. Saad M, Omrani AS, Baig K, Bahloul A, Elzein F, et al. (2014) Clinical aspects and outcomes of 70 patients with Middle East respiratory syndrome coronavirus infection: a single-center experience in Saudi Arabia. Int J Infect Dis 29: 301-306.

30. Feldmann H, Geisbert TW (2011) Ebola haemorrhagic fever. Lancet 377 : 849-862.

31. Gubler DJ (1998) Dengue and dengue hemorrhagic fever. Clin Microbiol Rev 11: 480-496.

32. Helms J, Severac F, Merdji H, Anglés-Cano E, Meziani F (2020) Prothrombotic phenotype in COVID-19 severe patients. Intensive Care Med 46: 1502-1503.

33. Bowles L, Platton S, Yartey N, Dave M, Lee K, et al. (2020) Lupus anticoagulant and abnormal coagulation tests in patients with COVID-19. N Engl J Med 383: 288-290.

34. Cummings MJ, Baldwin MR, Abrams D, Jacobson SD, Meyer BJ, et al (2020) Epidemiology, clinical course, and outcomes of critically ill adults with COVID-19 in New York City: a prospective cohort study. Lancet 395: $1763-1770$

35. Wu C, Chen X, Cai Y, Xia J, Zhou X, et al. (2020) Risk factors associated with acute respiratory distress syndrome and death in patients with coronavirus disease 2019 pneumonia in Wuhan, China. JAMA Intern Med 180: 934-943.

36. Asakura H (2014) Classifying types of disseminated intravascular coagulation: clinical and animal models. J Intensive Care 2: 20.

37. Wang J, Hajizadeh N, Moore EE, McIntyre RC, Moore PK, et al. (2020) Tissue plasminogen activator (tPA) treatment for COVID-19 associated acute respiratory distress syndrome (ARDS): A case series. J Thromb Haemost 18: 1752-1755. 
Citation: Haruta S (2020) Coagulation/Fibrinolysis and Thrombosis in Coronavirus Disease 2019: A Review Based on Up-To-Date Knowledge. J Emerg Med Trauma Surg Care S1: 006.

38. Helms J, Tacquard C, Severac F, Leonard-Lorant I, Ohana M, et al. (2020) High risk of thrombosis in patients with severe SARS-CoV-2 infection: multicenter prospective cohort study. Intensive Care Med 46: 1089-1098.

39. Liu J, Li J, Arnold K, Pawlinski R, Key NS (2020) Using heparin molecules to manage COVID-2019. Res Pract Thromb Haemost 4: 518-523.

40. Lindahl U, Li JP (2020) Heparin - An old drug with multiple potential targets in COVID-19 therapy. J Thromb Haemost 18: 2422-2424.

41. Thachil $\mathbf{J}$ (2020) The protective rather than prothrombotic fibrinogen in COVID-19 and other inflammatory states. J Thromb Haemost 18: 18491852 .

42. Hippensteel JA, LaRiviere WB, Colbert JF, Langouët-Astrié CJ, Schmidt EP (2020) Heparin as a therapy for COVID-19: current evidence and future possibilities. Am J Physiol Lung Cell Mol Physiol 319: L211-L217.

43. Tang N, Bai H, Chen X, Gong J, Li D, et al. (2020) Anticoagulant treatment is associated with decreased mortality in severe coronavirus disease 2019 patients with coagulopathy. J Thromb Haemost 18: 1094-1099.

44. Paranjpe I, Fuster V, Lala A, Russak AJ, Glicksberg BS, et al. (2020) Association of treatment dose anticoagulation with in-hospital survival among hospitalized patients with COVID-19. J Am Coll Cardiol 76: $122-$ 124.
45. Llitjos JF, Leclerc M, Chochois C, Monsallier JM, Ramakers M, et al. (2020) High incidence of venous thromboembolic events in anticoagulated severe COVID-19 patients. J Thromb Haemost 18: 1743-1746.

46. Hasan SS, Radford S, Kow CS, Zaidi STR (2020) Venous thromboembolism in critically ill COVID-19 patients receiving prophylactic or therapeutic anticoagulation: a systematic review and meta-analysis. J Thromb Thrombolysis 2020: 1-8.

47. Rossi R, Coppi F, Talarico M, Boriani G (2020) Protective role of chronic treatment with direct oral anticoagulants in elderly patients affected by interstitial pneumonia in COVID-19 era. Eur J Intern Med 77: 158-160.

48. Testa S, Prandoni P, Paoletti O, Morandini R, Tala M, et al. (2020) Direct oral anticoagulant plasma levels' striking increase in severe COVID-19 respiratory syndrome patients treated with antiviral agents: The Cremona experience. J Thromb Haemost 18: 1320-1323.

49. Thachil J, Tang N, Gando S, Falanga A, Cattaneo M, et al. (2020) ISTH interim guidance on recognition and management of coagulopathy in COVID-19. J Thromb Haemost 18: 1023-1026. 


\section{di \\ нетан}

Advances In Industrial Biotechnology | ISSN: 2639-5665

Advances In Microbiology Research | ISSN: 2689-694X

Archives Of Surgery And Surgical Education | ISSN: 2689-3126

Archives Of Urology

Archives Of Zoological Studies | ISSN: 2640-7779

Current Trends Medical And Biological Engineering

International Journal Of Case Reports And Therapeutic Studies | ISSN: 2689-310X Journal Of Addiction \& Addictive Disorders | ISSN: 2578-7276

Journal Of Agronomy \& Agricultural Science | ISSN: 2689-8292

Journal Of AIDS Clinical Research \& STDs | ISSN: 2572-7370

Journal Of Alcoholism Drug Abuse \& Substance Dependence | ISSN: 2572-9594

Journal Of Allergy Disorders \& Therapy | ISSN: 2470-749X

Journal Of Alternative Complementary \& Integrative Medicine | ISSN: 2470-7562

Journal Of Alzheimers \& Neurodegenerative Diseases | ISSN: 2572-9608

Journal Of Anesthesia \& Clinical Care | ISSN: 2378-8879

Journal Of Angiology \& Vascular Surgery | ISSN: 2572-7397

Journal Of Animal Research \& Veterinary Science | ISSN: 2639-3751

Journal Of Aquaculture \& Fisheries | ISSN: 2576-5523

Journal Of Atmospheric \& Earth Sciences | ISSN: 2689-8780

Journal Of Biotech Research \& Biochemistry

Journal Of Brain \& Neuroscience Research

Journal Of Cancer Biology \& Treatment | ISSN: 2470-7546

Journal Of Cardiology Study \& Research | ISSN: 2640-768X

Journal Of Cell Biology \& Cell Metabolism | ISSN: 2381-1943

Journal Of Clinical Dermatology \& Therapy | ISSN: 2378-8771

Journal Of Clinical Immunology \& Immunotherapy | ISSN: 2378-8844

Journal Of Clinical Studies \& Medical Case Reports | ISSN: 2378-8801

Journal Of Community Medicine \& Public Health Care | ISSN: 2381-1978

Journal Of Cytology \& Tissue Biology | ISSN: 2378-9107

Journal Of Dairy Research \& Technology | ISSN: 2688-9315

Journal Of Dentistry Oral Health \& Cosmesis | ISSN: 2473-6783

Journal Of Diabetes \& Metabolic Disorders | ISSN: 2381-201X

Journal Of Emergency Medicine Trauma \& Surgical Care | ISSN: 2378-8798

Journal Of Environmental Science Current Research | ISSN: 2643-5020

Journal Of Food Science \& Nutrition | ISSN: 2470-1076

Journal Of Forensic Legal \& Investigative Sciences | ISSN: 2473-733X

Journal Of Gastroenterology \& Hepatology Research | ISSN: 2574-2566
Journal Of Genetics \& Genomic Sciences | ISSN: 2574-2485

Journal Of Gerontology \& Geriatric Medicine | ISSN: 2381-8662

Journal Of Hematology Blood Transfusion \& Disorders | ISSN: 2572-2999

Journal Of Hospice \& Palliative Medical Care

Journal Of Human Endocrinology | ISSN: 2572-9640

Journal Of Infectious \& Non Infectious Diseases | ISSN: 2381-8654

Journal Of Internal Medicine \& Primary Healthcare | ISSN: 2574-2493

Journal Of Light \& Laser Current Trends

Journal Of Medicine Study \& Research | ISSN: 2639-5657

Journal Of Modern Chemical Sciences

Journal Of Nanotechnology Nanomedicine \& Nanobiotechnology | ISSN: 2381-2044

Journal Of Neonatology \& Clinical Pediatrics | ISSN: 2378-878X

Journal Of Nephrology \& Renal Therapy | ISSN: 2473-7313

Journal Of Non Invasive Vascular Investigation | ISSN: 2572-7400

Journal Of Nuclear Medicine Radiology \& Radiation Therapy | ISSN: 2572-7419

Journal Of Obesity \& Weight Loss | ISSN: 2473-7372

Journal Of Ophthalmology \& Clinical Research | ISSN: 2378-8887

Journal Of Orthopedic Research \& Physiotherapy | ISSN: 2381-2052

Journal Of Otolaryngology Head \& Neck Surgery | ISSN: 2573-010X

Journal Of Pathology Clinical \& Medical Research

Journal Of Pharmacology Pharmaceutics \& Pharmacovigilance | ISSN: 2639-5649

Journal Of Physical Medicine Rehabilitation \& Disabilities | ISSN: 2381-8670

Journal Of Plant Science Current Research | ISSN: 2639-3743

Journal Of Practical \& Professional Nursing | ISSN: 2639-5681

Journal Of Protein Research \& Bioinformatics

Journal Of Psychiatry Depression \& Anxiety | ISSN: 2573-0150

Journal Of Pulmonary Medicine \& Respiratory Research | ISSN: 2573-0177

Journal Of Reproductive Medicine Gynaecology \& Obstetrics | ISSN: 2574-2574

Journal Of Stem Cells Research Development \& Therapy | ISSN: 2381-2060

Journal Of Surgery Current Trends \& Innovations | ISSN: 2578-7284

Journal Of Toxicology Current Research | ISSN: 2639-3735

Journal Of Translational Science And Research

Journal Of Vaccines Research \& Vaccination | ISSN: 2573-0193

Journal Of Virology \& Antivirals

Sports Medicine And Injury Care Journal | ISSN: 2689-8829

Trends In Anatomy \& Physiology | ISSN: 2640-7752

Submit Your Manuscript: https://www.heraldopenaccess.us/submit-manuscript 